\title{
Implications of prolonged milking time on time budgets and lying behavior of cows in large pasture-based dairy herds
}

\author{
D. S. Beggs, ${ }^{1}$ E. C. Jongman, P. E. Hemsworth, and A. D. Fisher \\ Animal Welfare Science Centre, Faculty of Veterinary and Agricultural Sciences, University of Melbourne, Australia 3010
}

\begin{abstract}
In large Australian pasture-based dairy herds, it is common for the time taken to milk a herd of cows to be up to $4 \mathrm{~h}$. Cows are collected from the paddock as a group, wait in turn in the dairy yard to be milked, and then return individually to the paddock or feed pad immediately after leaving the milking parlor. In such herds, we previously found a consistent milking order, resulting in some cows being regularly away from pasture for several hours per day more than others. Increased time away from pasture may affect the time budgets of cows because of decreased opportunity for grazing or lying down. Lying behavior is a high-priority behavior for cows, and the duration of lying has been used as an important measure of their welfare. We applied activity monitors for $7 \mathrm{~d}$ to 15 cows toward the beginning and 15 cows toward the end of the milking order in 10 dairy herds milking 500 to 730 cows as a single group to understand the effect of extra time spent in the dairy on lying behavior. Study cows typically produced 6,000 to $8,000 \mathrm{~L}$ in a 300 -d lactation on rotary dairy platforms with 40 to 80 units, being fed 2.5 to $6 \mathrm{~kg}$ of grain mix in the milking parlor daily, with the rest of the diet being supplied as pasture or forage provided in the pasture or close to the exit of the dairy. Over the 10 farms, 1,948 cow-days were available for analysis. The furthest paddocks on each farm were 1.8 to $3.5 \mathrm{~km}$ walking distance from the dairy. A wide range of steps were taken each day, ranging from 1,705 to 15,075 (mean $=5,916)$. The main predictor of the number of steps was the farm on which the cows were located. Cows that spent less than an hour waiting to be milked (and would be unlikely to have their ability to lie down affected by the milking process) laid down for a mean of $9.8 \mathrm{~h} / \mathrm{d}$. Steps walked and delay in the dairy waiting to be milked were both significantly associated with lying time, but the effect was not large. A regression model accounting for the waiting time at
\end{abstract}

Received May 12, 2018.

Accepted August 5, 2018.

${ }^{1}$ Corresponding author: dbeggs@unimelb.edu.au the dairy, steps taken, cow age, and farm was used to investigate the relationship with daily lying time. For every 1,000 steps, lying time reduced by $0.49 \mathrm{~h}$; however, the number of steps explained only $1 \%$ of the variation in lying time. For every hour increase in waiting time at the dairy, lying decreased by approximately $14 \mathrm{~min}$, but this explained only $14 \%$ of the variation in lying. We concluded that milking time durations of 2 to $4 \mathrm{~h}$, common in large Australian pasture-based dairy herds, did not significantly affect the time budget for lying of individual cows in our study herds. Whereas the effect of long milking times does not appear to be a major risk to animal welfare in terms of lying time, the effect on cow health and production warrants further investigation.

Key words: dairy cow, lying time, animal welfare, time budget

\section{INTRODUCTION}

In contrast to many countries, Australian dairy farms are predominantly pasture-based, with few farms having lactating cows housed indoors at all. Approximately 60 to $65 \%$ of cattle feed requirements come from grazing, and the feeding of TMR is rare (Dairy Australia, 2017a). However, similar to many countries, there has been a trend toward increasing herd sizes. Farms milking more than 500 cows are now common and, in a recent survey of Australian dairy farmers, $73 \%$ of farmers milking more than 700 cows in 2017 expected to increase numbers further over the next $2 \mathrm{yr}$ (Dairy Australia, 2017b). The increasing herd size and intensification of pasture-based dairy production, such as occurs in Australia and New Zealand, has occurred against a background of a heightened public interest in animal welfare (Fisher and Webster, 2013; von Keyserlingk and Weary, 2017; Weary and von Keyserlingk, 2017). Potential challenges to pasture-based dairy cow welfare that have been identified with increasing herd size include the long distances cows are required to walk to and from the dairy parlor and extended time spent at the dairy waiting to be milked (Clark et al., 2013; Beggs et al., 2015, 2018; Webster et al., 2015). 
In Australian pasture-based dairy herds, cows are generally milked twice per day. Between milkings, cows spend their time in paddocks, which may be up to 4 $\mathrm{km}$ walking distance from the dairy. It is common for cows to be collected from the paddock as a group, to wait in turn in the dairy yard to be milked, and to return individually to the paddock (sometimes passing through a feed pad where hay or silage is available not far from the exit of the dairy) immediately after leaving the milking parlor. It is very common for cows to return to different paddocks each day, and in many cases the night paddock is different from the day paddock. When cows are grazing in paddocks further from the dairy, the time away from pasture for the whole herd will be increased as they walk to and from the dairy, which may be associated with an increase in the number of steps taken. When cows wait at the dairy to be milked, the time away from pasture wil be increased, and that will affect individuals differently, depending on their place in the milking order. Increased time away from pasture may affect the time budgets of cows because of decreased opportunity for grazing or lying down, which may in turn affect their welfare. Lying is a high-priority behavior for dairy cows, and the frequency and duration of lying behavior have been used as important measures of their welfare (Munksgaard et al., 2005). Considerable evidence exists that restricting lying behavior causes stress and reduces animal welfare outcomes (Munksgaard and Simonsen, 1996; Fisher et al., 2002). Mean voluntary lying times for pasturebased dairy cows milked twice daily are reported to be between 9 and $11 \mathrm{~h}$ (Krohn and Munksgaard, 1993; Botheras, 2006; Hetti Arachchige et al., 2013).

In a survey of 863 Australian dairy farmers, the time taken to milk a herd of more than 500 cows was commonly up to $4 \mathrm{~h}$. On most farms paddocks were located where cows would be off pasture for a single milking for more than $3.5 \mathrm{~h}$, and the mean walking distance to the furthest paddock was more than $2 \mathrm{~km}$ (Beggs et al., 2015). Thus, the time cows are out of the paddock can be considerable.

Previous work has demonstrated that, in such herds, there is a consistency to the order in which cows are milked and, in particular, cohorts of cows are regularly milked in the first and last $20 \%$ of the milking order (Beggs et al., 2018). Thus, in herds where it takes up to $4 \mathrm{~h}$ to milk all cows and cows are milked twice daily, it is likely a cohort of cows regularly has 8-h longer waiting time in the dairy yard (and thus potentially 8-h less on pasture) than other cows in the same herd.

The time cows spend lying will depend on the competing motivations to graze and perform other functions that require standing (e.g., elimination, self-grooming).
Whereas grazing time would likely vary with pasture availability and supplementary feeding levels, various studies have reported the typical time spent grazing for lactating cows at pasture to be approximately 8 to $9 \mathrm{~h}$ (Bargo et al., 2002a,b; Botheras, 2006; Pérez-Prieto et al., 2011).

If cows are motivated to spend approximately $8 \mathrm{~h}$ grazing and $10 \mathrm{~h}$ lying down, it seems reasonable to hypothesize that the time budgets of cows might be affected when cows spend more than $6 \mathrm{~h}$ (or $240 \mathrm{~min}$ ) away from pasture per day, and, accordingly, this might affect their welfare. To our knowledge, the time budgets (walking, standing, and lying) of dairy cows in large pasture-based dairy herds where the milking process takes more than $3 \mathrm{~h}$, such as are common in Australia, have not been previously examined. The amount of time cows spend walking, standing, and lying can be measured electronically through activity monitors applied to the hind limb of cattle using an ankle bracelet (e.g., IceTags, Ice Robotics Ltd., Roslin, UK). We applied activity monitors to cows in 10 large pasturebased Australian dairy herds to (1) determine the time spent standing and lying in typical, large Australian pasture-based dairy herds, and (2) investigate whether increased time out of the paddock due to being milked later in the milking order or walking long distances affects cow lying time.

\section{MATERIALS AND METHODS}

This study was conducted with approval from the University of Melbourne Faculty of Veterinary Science Animal Ethics Committee. Ten dairy herds known to the authors were selected for the study by invitation based on milking more than 500 cows as a single group over a period of 2 to $4 \mathrm{~h}$, having infrastructure that recorded daily milking times of individual cows, and agreement to participate in the study.

To generate a data set that included cows milked toward the beginning and the end of the milking order, we selected 15 cows as they were being milked in the first $20 \%$ of the milking order and 15 cows that were milked in the last $20 \%$ of the milking order on the day of device application. Cows were selected to ensure a representative age range in each group (at least 4 cows in the age ranges of $2,3-5$, and $6+\mathrm{yr}$ old). Cows were not selected if they showed any obvious clinical abnormality or if they were lame on the day of selection. Activity monitors (IceTags) were applied to a hind leg of each cow for $7 \mathrm{~d}$.

Milking records, including the time each cow was milked and the position in the milking order, were obtained from the dairy infrastructure for all cows at each 
milking during the study period and imported into Microsoft Excel (Microsoft Excel 2016, Microsoft Corp., Redmond, WA). The time elapsed between when the first cow was milked and the time the study cow was milked was calculated for each milking. The daily waiting time (WT) was calculated for each cow day as the sum of the time spent waiting to be milked from the morning and afternoon milking. As all cows on a given day walked from and returned to the same paddock, we considered WT to be an approximation of the extra time out of the paddock that was because of the milking duration relative to other cows. The number of steps taken $(\mathbf{S T})$ and the mean daily lying time $(\mathbf{L T})$ were calculated using the IceTag algorithm for a 24 -h period starting from approximately the time the cows finished the morning milking. We did not interfere with normal farm management in terms of the paddocks that cows were placed in following each milking.

Cases were excluded from analysis where data were missing (e.g., because the dairy infrastructure had not recorded the cow entering the dairy or a full 24-h data were not available) or where it was biologically implausible, presumably due to IceTag failure. Statistical analyses were performed using SPSS (version 25, IBM Corp., Armonk, NY). The descriptive statistics and scatter graph functions were used to investigate the distribution of ST and LT.

We hypothesized that the number of steps taken in a day would be largely influenced by the farm, as the farms varied in size and geography. Within each farm, we hypothesized that the distance walked from the milking parlor to the paddock, which varied each day according to routine farm management, would be a major predictor of the number of steps as might age of the cow. To test this hypothesis, a 3-stage hierarchical multiple regression was conducted with ST as the outcome variable. Farm was entered at stage 1 of the regression mode, with date being added as a categorical predictor at stage 2 and age as a linear predictor at stage 3 .

The effect of ST and WT on LT was first investigated at the univariable cow-day level. To account for differences between individual cows and the possible confounding effect of different farms, a linear regression model was created, using LT as outcome variable, and using the age, farm, and the mean ST and WT over the experimental period as predictors.

To assess whether extremes of waiting time at the dairy affected LT, an independent-samples $t$-test was used to compare the mean LT of cows with mean WT $<1 \mathrm{~h}$ (cows which would not be expected to have their lying time affected by WT) with cows that had a WT $>4$ h.
Table 1. Hierarchical multiple regression model showing the effect of adding date and age to the effect of farm for predicting the mean steps taken over 1,948 cow days

\begin{tabular}{lcc}
\hline Model predictors & $\mathrm{R}^{2}$ & $\mathrm{SE}$ \\
\hline Farm & 0.519 & 1.057 \\
Farm, date & 0.520 & 1.057 \\
Farm, date, age & 0.521 & 1.055 \\
\hline
\end{tabular}

\section{RESULTS}

All farms were milking between 520 and 730 Holstein or Holstein-cross cows on rotary dairy platforms with 40 to 80 units. Cows on the study farms typically produce 6,000 to $8,000 \mathrm{~L}$ in a $300-d$ lactation, and they were being fed 2.5 to $6 \mathrm{~kg}$ of grain mix twice daily on the platform while being milked. Walking distance from the dairy to the furthest paddock ranged from 1.8 to $3.5 \mathrm{~km}$. Prior to the study, farmers estimated that the typical time taken to milk all cows was 150 to $210 \mathrm{~min}$. All cows had calved at least $50 \mathrm{~d}$ at the beginning of the study. Data from 10 cows were excluded because the activity meters failed (a maximum of 3 on any one farm). No cows became lame during the study. Over the 10 farms, we had 1,948 cow-days available for analysis.

The distribution of daily lying time is shown in Figure 1 . We found wide range of ST, ranging from 1,705 to 15,075 (mean $=5,916$; median $=5,812)$. The effect of adding date and age to the effect of farm on predicting ST in a linear regression model is shown in Table 1.

We also found a wide range of WT, with data for at least 60 cow-days in every 30-min increment WT of 0 min through to $6 \mathrm{~h}$. The mean WT of $96 \min (\mathrm{SD}=89)$ for cows selected in the first $20 \%$ of the milking order was significantly less the mean WT of $270 \mathrm{~min}$ ( SD =

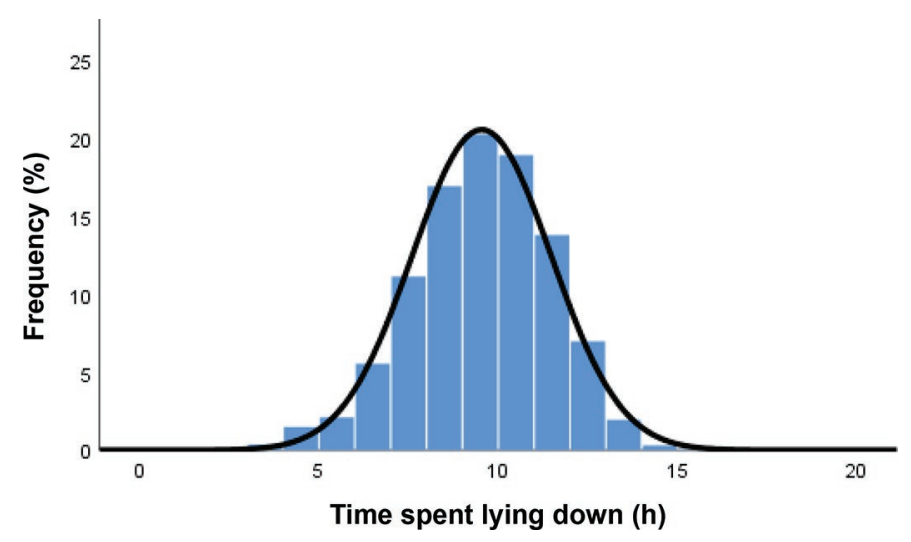

Figure 1. Histogram showing the distribution of daily lying time in hours of pasture-based dairy cows on 10 farms over 1,948 cow-days. $($ mean $=9.53, \mathrm{SD}=1.95$, median $=9.65)$. Color version available online. 
Table 2. Linear regression showing the relationship among mean steps taken, mean waiting time at the dairy, age, and time spent lying down for 291 cows over a 7 -d period in 10 herds

\begin{tabular}{lccccc}
\hline Model $^{1}$ & $\begin{array}{c}\text { Unstandardized } \\
\text { coefficient }(\beta)\end{array}$ & SE & P-value & 95\% CI & $\begin{array}{c}\text { Partial eta squared }\left(\eta_{\mathrm{p}}{ }^{2}\right) \\
\text { (proportion of variation in lying explained) }\end{array}$ \\
\hline (Constant) & 14.2 & 0.74 & $<0.001$ & 12.7 to 15.6 & 0.57 \\
Steps $(\times 1,000)$ & -0.49 & 0.094 & $<0.001$ & -0.67 to -0.31 & 0.01 \\
Waiting time $(\mathrm{h})$ & -0.24 & 0.36 & $<0.001$ & -0.31 to -0.17 & 0.14 \\
Age & -0.04 & 0.029 & 0.14 & -0.1 to 0.01 & 0.09 \\
\hline
\end{tabular}

${ }^{1}$ The model also accounted for the effect of individual farm; data not shown.

$81, P<0.001)$ for cows selected in the last $20 \%$ of the milking order. Both WT and ST were graphed against time spent lying (Figures 2 and 3), which did not show an obvious strong relationship.

At the cow level, we found a wide range of mean WT over the study period, with at least 30 cows being represented in each group of waiting times for 1-h increments of 1 to $6 \mathrm{~h} / \mathrm{d}$. The mean ST was approximately 6,000 steps per day $(\mathrm{SD}=1,300)$ and the mean $\mathrm{LT}$ was $9.48 \mathrm{~h} / \mathrm{d}(\mathrm{SD}=1.3)$. Of the cows, $11 \%$ had a mean LT of less than $8 \mathrm{~h}$. The linear regression model showing effect of farm, age, ST, and WT over the study period is shown in Table 2. The mean LT for cows with a WT $>4 \mathrm{~h}$ was $9.1 \mathrm{~h}(\mathrm{n}=44, \mathrm{SD}=1.2)$ compared with 9.9 $\mathrm{h}(\mathrm{n}=117, \mathrm{SD}=1.3)$ for cows that waited $<1 \mathrm{~h}(P<$ $0.001)$.

\section{DISCUSSION}

IceTags have been previously used to record the duration and frequency of lying, standing, and activity in cattle (e.g., Bewley et al., 2010; Tolkamp et al., 2010; Maselyne et al., 2017). Their use for detecting lying and walking has been validated in pasture-based dairy cattle in a study that reported that $95 \%$ of lying data

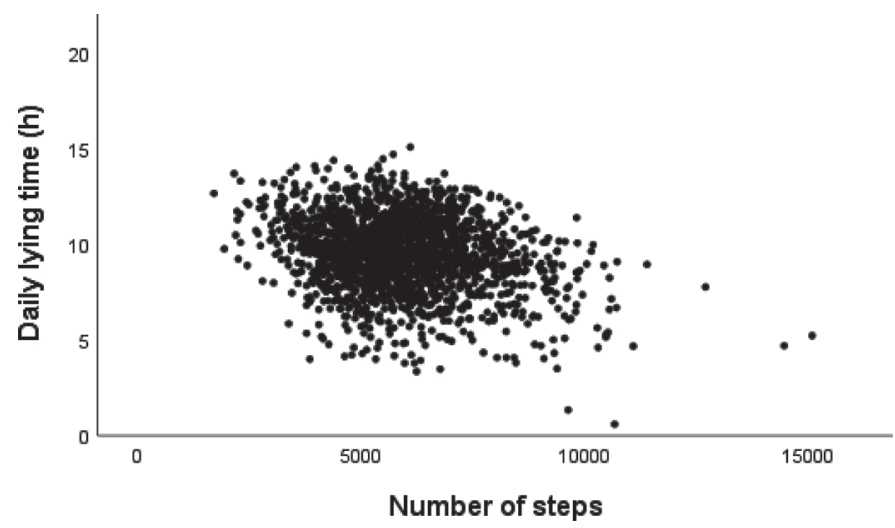

Figure 2. Scatter plot showing the relationship between total steps taken and hours of lying time in the same 24 -h period for 1,948 cowdays on 10 farms; $\mathrm{R}^{2}=0.058$. points were within 1 percentage point of observed data and $95 \%$ of stepping data were within 3 percentage points (McGowan et al., 2007). A potential limitation of our study is that we did not further validate the devices in detail. We assessed data from the devices for being biologically plausible and noted that the devices recorded constant walking at times consistent with when the cows would have been walking to and from the dairy, and the devices did not report cows lying down during the times when cows would have been in the dairy yard.

\section{Lying Time}

In our study, the mean daily lying time of $9.53 \mathrm{~h}$ was toward the lower end of the range of values commonly recorded for dairy cows. Whereas considerable individual variation exists between cows, most studies report mean or median lying times of more than $10 \mathrm{~h}$. As well as being constrained by time available to lie down, lying times can vary with stage of lactation, milk yield, body condition, lameness, estrus, supplementary feeding rate, and other factors (Bewley et al., 2010; Charlton et al., 2014; Maselyne et al., 2017; Silper et al., 2017). Considerable variation also exists between

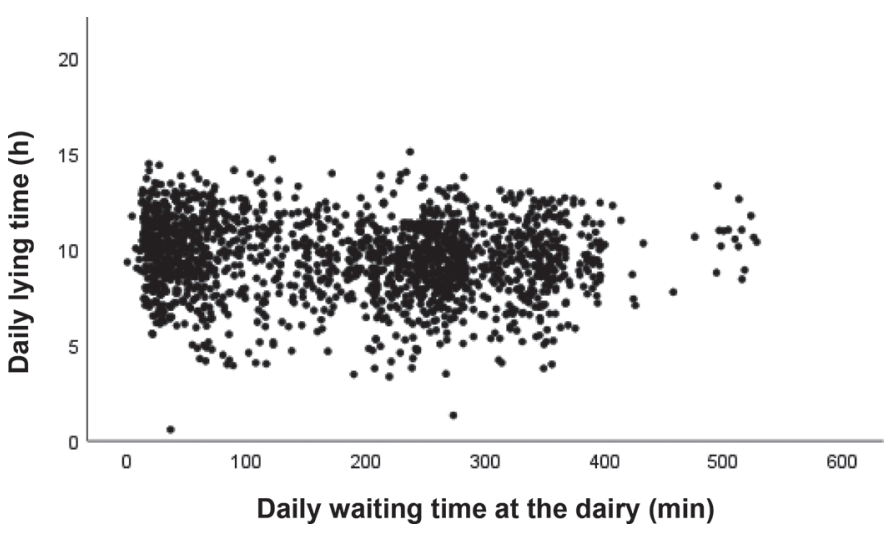

Figure 3. Scatter plot showing the relationship between time waiting to be milked and hours of lying time in the same 24 -h period for 1,948 cow-days on 10 farms; $\mathrm{R}^{2}=0.014$. 
cows; for example, in a study of automated milking systems, where it was hypothesized that cows would be less constrained in their ability to lie down, the median lying time was $11.4 \mathrm{~h} / \mathrm{d}$, but even in this system $25 \%$ of cows laid for less than $9.7 \mathrm{~h}$ (Westin et al., 2016). In our study, we also noted wide variation in lying times, even in cows with a mean WT less than 60 min, which would be unlikely to have constrained their lying time. These cows had a mean lying time of only $9.9 \mathrm{~h}$, suggesting that many cows in large Australian pasture-based dairy herds choose to lie down for less than $10 \mathrm{~h} / \mathrm{d}$.

Lying is a high-priority behavior for dairy cows, and previous studies have reported they will sacrifice other behaviors such as grazing and social behavior to a greater extent than they sacrifice lying behavior when time is constrained (Munksgaard et al., 2005; Cooper et al., 2007). This is consistent with our data. As seen in Figure 3, more than half the cows with a WT of $>500$ min (which would likely have been away from pasture for 10 or more hours after taking into account walking time) had lying times of at least $10 \mathrm{~h}$. Presumably, these cows reduced other behaviors to do so.

\section{Steps Taken}

We hypothesized that a major contribution to the number of steps cows take in a day would be the distance from the milking parlor to the paddock. Farmers in our study generally grazed cows in a different paddock each day and often used different day and night paddocks. As expected, because all cows on a given farm grazed in the same paddocks and walked the same distance to the dairy each day, farm was a major predictor of the mean ST, with nearly $52 \%$ of variation in ST being explained by farm alone $\left(\mathrm{R}^{2}=0.519\right)$. When date and age were added to the model, the variation in ST explained by the model only increased to $52.1 \%$, suggesting that difference in daily walking distance was only a minor contributor to ST. Figure 2 shows that, at a univariable level, a relationship exists between ST and LT, but it is not strong, explaining less than $6 \%$ of the variation in LT. Perhaps this result is not surprising, as it is likely that a typical distance walked to and from the paddock each day was approximately $4 \mathrm{~km}$. The mean stride length of Holstein cattle walking on a track has been estimated at between approximately 130 and $165 \mathrm{~cm}$, and walking speed has been estimated at approximately 4 to $5 \mathrm{~km} / \mathrm{h}$ (Carvalho et al., 2007; Telezhenko, 2009; Alsaaod et al., 2015). The walking speed of cows in a large group constrained by a narrow track is likely to be lower than this, and, in a study of New Zealand pasture-based cows in herds of 350 to 380 cows, the average walking pace of cows was ap- proximately $3 \mathrm{~km} / \mathrm{h}$. At a stride length of $1.5 \mathrm{~m}$, only 3,333 steps would be required walking to and from the dairy-less than half the mean daily ST recorded in our study - and this would take less than $1.5 \mathrm{~h}$ out of a 24-h day.

\section{Relationship Among Steps, Delay in the Dairy, and Lying Time}

As shown in Table 2, ST and WT were both significantly associated with LT. For every 1,000 steps, lying time reduced by $0.49 \mathrm{~h}$; however, this needs to be interpreted with caution because the number of steps explained only $1 \%$ of the variation in lying time. Association exists between ST and LT, but our data cannot conclude that it is causal. Indeed, it seems logical that cows that spend less time lying for any reason would spend more time walking. For every hour increase in waiting time at the dairy, lying time decreased by approximately $14 \mathrm{~min}$, but this explained only $14 \%$ of the variation in lying time. Cows that waited more than 4 $\mathrm{h}$ at the dairy laid on average 48 min less than cows milked within the hour, but we still noted significant overlap with the standard deviation of both groups being more than an hour.

Our data showed that time spent at the dairy waiting to be milked did not have a major effect on the lying time of individual cows, which seem to be very inelastic. Thus, it seems that typical times of 2 to $4 \mathrm{~h}$ taken to milk large Australian pasture-based dairy herds do not constitute a major animal welfare issue because of restricted ability to lie down.

Presumably, if cows spend several hours less in the paddock, but do not spend much less time lying down, they must spend less time undertaking other behaviors such as grazing, idling, and social interactions. Cows milked toward the end of the milking order would not only have less time in the paddock to graze, but less grass would also likely be available. In one Australian study where cows entered the paddock following milking over a 90 -min period, $70 \%$ of the pasture mass had been consumed before the last cow entered the paddock (Scott et al., 2014). Previous studies have shown that both competition as well as restricted amount of food can increase the rate of feed intake (Nielsen et al., 2000; Munksgaard et al., 2005). Although we did not specifically analyze milking order consistency, the mean WT for cows selected in the last $20 \%$ of the milking order was nearly $3 \mathrm{~h}$ more than for cows selected in the last $20 \%$ of the milking order. This result suggests that cows can be consistently early or late in the milking order, and thus some individual cows would be consistently affected more by longer milking duration than others 
within a herd. The implications of potential reduced grazing time on cow health and production warrant further investigation.

\section{CONCLUSIONS}

Considerable variation exists in the lying time of individual cows in large Australian pasture-based herds. Cows may spend 1 to $3 \mathrm{~h}$ walking to and from the dairy and a further 6 to $8 \mathrm{~h}$ waiting to be milked during a day. The time taken to milk a herd of cows is commonly 2 to $4 \mathrm{~h}$, and some cows may regularly be away from the paddock for several hours more than others, although this did not significantly affect the time budget for lying in our study cows. The effect of long milking times does not appear to be a major risk to animal welfare in terms of lying time, but the effect on cow health and production warrants further investigation.

\section{ACKNOWLEDGMENTS}

The authors are grateful to the staff of the Warrnambool Veterinary Clinic and the farmers who graciously allowed us on their farms. We acknowledge the Victorian Department of Economic Development Jobs Transport and Resources and Dairy Australia Ltd. for their support of this project. This project was also supported through an Australian Government Research Training Program Scholarship.

\section{REFERENCES}

Alsaaod, M., J. J. Niederhauser, G. Beer, N. Zehner, G. SchuepbachRegula, and A. Steiner. 2015. Development and validation of a novel pedometer algorithm to quantify extended characteristics of the locomotor behavior of dairy cows. J. Dairy Sci. 98:6236-6242. https://doi.org/10.3168/jds.2015-9657.

Bargo, F., L. D. Muller, J. E. Delahoy, and T. W. Cassidy. 2002a. Milk response to concentrate supplementation of high producing dairy cows grazing at two pasture allowances. J. Dairy Sci. 85:17771792. https://doi.org/10.3168/jds.S0022-0302(02)74252-5.

Bargo, F., L. D. Muller, J. E. Delahoy, and T. W. Cassidy. 2002b. Performance of high producing dairy cows with three different feeding systems combining pasture and total mixed rations. J. Dairy Sci. 85:2948-2963. https://doi.org/10.3168/jds.S0022-0302(02)74381 -6 .

Beggs, D. S., A. D. Fisher, E. C. Jongman, and P. E. Hemsworth. 2015. A survey of Australian dairy farmers to investigate animal welfare risks associated with increasing scale of production. J. Dairy Sci. 98:5330-5338. https://doi.org/10.3168/jds.2014-9239.

Beggs, D. S., E. C. Jongman, P. H. Hemsworth, and A. D. Fisher. 2018. Short communication: Milking order consistency of dairy cows in large Australian herds. J. Dairy Sci. 101:603-608. https:// doi.org/10.3168/jds.2017-12748.

Bewley, J. M., R. E. Boyce, J. Hockin, L. Munksgaard, S. D. Eicher, M. E. Einstein, and M. M. Schutz. 2010. Influence of milk yield, stage of lactation, and body condition on dairy cattle lying behaviour measured using an automated activity monitoring sensor. J. Dairy Res. 77:1-6. https://doi.org/10.1017/S0022029909990227.
Botheras, N. A. 2006. The behaviour and welfare of grazing dairy cows (Bos taurus): Effects of time away from pasture. PhD Thesis. Faculty of Land and Food Resources. University of Melbourne, Melbourne, Australia.

Carvalho, V., R. A. Bucklin, J. K. Shearer, L. Shearer, I. A. Naas, and M. Neto. 2007. Dairy cattle linear and angular kinematics during the stance phase. Agric. Eng. IX:1-10.

Charlton, G. L., D. B. Haley, J. Rushen, and A. M. de Passillé. 2014. Stocking density, milking duration, and lying times of lactating cows on Canadian freestall dairy farms. J. Dairy Sci. 97:26942700. https://doi.org/10.3168/jds.2013-6923.

Clark, D., B. Malcolm, and J. Jacobs. 2013. Dairying in the antipodes: Recent past, near prospects. Anim. Prod. Sci. 53:882-893. https:/ /doi.org/10.1071/AN12281.

Cooper, M. D., D. R. Arney, and C. J. C. Phillips. 2007. Two- or fourhour lying deprivation on the behavior of lactating dairy cows. J. Dairy Sci. 90:1149-1158. https://doi.org/10.3168/jds.S0022 -0302(07)71601-6.

Dairy Australia. 2017a. Australian Dairy Industry In Focus 2017. Dairy Australia Limited, Southbank, Victoria, Australia.

Dairy Australia. 2017b. Dairy Situation and Outlook 2017. Dairy Australia Ltd., Melbourne, Australia.

Fisher, A. D., G. A. Verkerk, C. J. Morrow, and L. R. Matthews. 2002. The effects of feed restriction and lying deprivation on pituitary-adrenal axis regulation in lactating cows. Livest. Prod. Sci. 73:255-263. https://doi.org/10.1016/S0301-6226(01)00246-9

Fisher, A. D., and J. R. Webster. 2013. Dairy cow welfare: The role of research and development in addressing increasing scrutiny. Anim. Prod. Sci. 53:924-930. https://doi.org/10.1071/AN12276.

Hetti Arachchige, A. D., A. D. Fisher, M. J. Auldist, W. J. Wales, and E. C. Jongman. 2013. Effects of different systems of feeding supplements on time budgets of cows grazing restricted pasture allowances. Appl. Anim. Behav. Sci. 148:13-20. https://doi.org/10 .1016/j.applanim.2013.08.002.

Krohn, C. C., and L. Munksgaard. 1993. Behaviour of dairy cows kept in extensive (loose housing/pasture) or intensive (tie stall) environments II. Lying and lying-down behaviour. Appl. Anim. Behav. Sci. 37:1-16. https://doi.org/10.1016/0168-1591(93)90066-X.

Maselyne, J., M. Pastell, P.T. Thomsen, V.M. Thorup, L. Hanninen, J. Vangeyte, A. Van Nuffel, and L. Munksgaard. 2017. Daily lying time, motion index and step frequency in dairy cows change throughout lactation. Res. Vet. Sci. 110:1-3. https://doi.org/10 .1016/j.rvsc.2016.10.003.

McGowan, J. E., C. R. Burke, and J. Jago. 2007. Validation of a technology for objectively measuring behaviour in dairy cows and its application for oestrous detection. Proc. N.Z. Soc. Anim. Prod. $67: 136-142$.

Munksgaard, L., M. B. Jensen, L. J. Pedersen, S. W. Hansen, and L. Matthews. 2005. Quantifying behavioural priorities-Effects of time constraints on behaviour of dairy cows, Bos taurus. Appl. Anim. Behav. Sci. 92:3-14. https://doi.org/10.1016/j.applanim .2004.11.005.

Munksgaard, L., and H.B. Simonsen. 1996. Behavioral and pituitary adrenal-axis responses of dairy cows to social isolation and deprivation of lying down. J. Anim. Sci. 74:769-778.

Nielsen, B. L., R. F. Veerkamp, and A. B. Lawrence. 2000. Effects of genotype, Feed type and lactational stage on the time budget of dairy cows. Acta Agric. Scand. Anim. Sci. 50:272-278. https://doi .org/10.1080/090647000750069467.

Pérez-Prieto, L. A., J. L. Peyraud, and R. Delagarde. 2011. Pasture intake, milk production and grazing behaviour of dairy cows grazing low-mass pastures at three daily allowances in winter. Livest. Sci. 137:151-160. https://doi.org/10.1016/j.livsci.2010.10.013.

Scott, B. A., A. Camacho, H. Golder, J. Molfino, K. L. Kerrisk, I. Lean, and S. C. Garcia. 2014. The nutritive value of pasture ingested by dairy cows varies within a herd. Pages 343-346 in 5th Australasian Dairy Science Symposium. Australian Dairy Science Symposium Committee, Hamilton, New Zealand.

Silper, B. F., A. M. L. Madureira, L. B. Polsky, S. Soriano, A. F. Sica, J. L. M. Vasconcelos, and R. L. A. Cerri. 2017. Daily lying 
behavior of lactating Holstein cows during an estrus synchronization protocol and its associations with fertility. J. Dairy Sci 100:8484-8495. https://doi.org/10.3168/jds.2016-12160.

Telezhenko, E. 2009. Measurement of spatial gait parameters from footprints of dairy cows. Animal 3:1746-1753. https://doi.org/10 $.1017 /$ S1751731109990644.

Tolkamp, B. J., M. J. Haskell, F. M. Langford, D. J. Roberts, and C. a. Morgan. 2010. Are cows more likely to lie down the longer they stand? Appl. Anim. Behav. Sci. 124:1-10. https://doi.org/10 .1016/j.applanim.2010.02.004.

von Keyserlingk, M. A. G., and D. M. Weary. 2017. A 100-Year Review: Animal welfare in the Journal of Dairy Science - The first 100 years. J. Dairy Sci. 100:10432-10444. https://doi.org/10.3168/ jds.2017-13298.
Weary, D. M., and M. A. G. von Keyserlingk. 2017. Public concerns about dairy-cow welfare: How should the industry respond? Anim. Prod. Sci. 57:1201-1209. https://doi.org/10.1071/AN16680.

Webster, J. R., K. E. Schütz, M. A. Sutherland, M. Stewart, and D. J. Mellor. 2015. Different animal welfare orientations towards some key research areas of current relevance to pastoral dairy farming in New Zealand. N. Z. Vet. J. 63:31-36. https://doi.org/10.1080/ 00480169.2014.958117.

Westin, R., A. Vaughan, A. M. de Passillé, T. J. DeVries, E. A. Pajor, D. Pellerin, J. M. Siegford, E. Vasseur, and J. Rushen. 2016. Lying times of lactating cows on dairy farms with automatic milking systems and the relation to lameness, leg lesions, and body condition score. J. Dairy Sci. 99:551-561. https://doi.org/10.3168/jds 2015-9737. 